\title{
Effect of an $E D A-A 1$ gene mutant on the proliferation and cell cycle distribution of cultured human umbilical vein endothelial cells
}

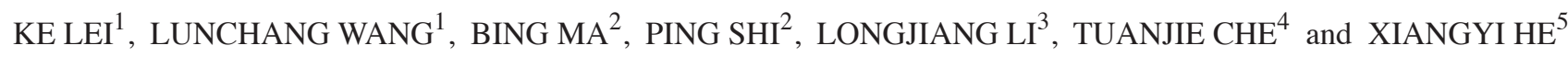 \\ Departments of ${ }^{1}$ Stomatology and ${ }^{2}$ Respiratory Medicine, Central Hospital of Guangyuan, Guangyuan, Sichuan 628000; \\ ${ }^{3}$ State Key Laboratory of Oral Diseases, Sichuan University, Chengdu, Sichuan 610041; ${ }^{4}$ Institute of Cell Biology, \\ School of Life Science; ${ }^{5}$ Department of Prosthodontics, School of Stomatology, \\ Lanzhou University, Lanzhou, Gansu 730000, P.R. China
}

Received October 25, 2014; Accepted November 12, 2015

DOI: $10.3892 /$ etm.2015.2952

\begin{abstract}
Ectodysplasin (EDA) gene mutation is associated with hypohidrotic ectodermal dysplasia (HED). The aim of this study was to investigate the effect of ectodysplasin, transcript variant $1(E D A-A 1)$ on the proliferation and cell cycle of ECV304 human umbilical vein endothelial cells (HUVECs). Recombinant eukaryotic expression vectors containing mutant (M) and wild-type (W) EDA-Al coding sequences, pcDNA3.1 (-)-EDA-A1-M and pcDNA3.1 (-)-EDA-A1-W, respectively, were transfected into ECV304 cells. The EDA-AI gene was amplified by reverse transcription polymerase chain reaction (RT-PCR), and the protein was detected by western blotting. The EDA-Al gene and protein were detected in ECV304 cells transfected with pcDNA3.1 (-)-EDA-A1-M and pcDNA3.1 (-)-EDA-A1-W, but not in ECV304 cells transfected with empty plasmid or cells that had not undergone transfection. Compared with the control group, the EDA-Al gene mutant significantly decreased the proliferation of ECV304 cells and its inhibition rate was $45.70 \%(\mathrm{P}<0.01)$, whereas the wild-type $E D A-A 1$ gene did not cause such growth inhibition $(\mathrm{P}>0.05)$. A significant increase of the fraction of cells in the $\mathrm{G}_{0} / \mathrm{G}_{1}$ phase of the cell cycle was observed in the ECV304 cells of the mutant group compared with wild type group, with an increase in the $\mathrm{S}$ phase population and a concomitant reduction in the $\mathrm{G}_{2} / \mathrm{M}$ phase population $(\mathrm{P}<0.05)$. These results indicate that compared with the wild-type gene, transfection with a mutant $E D A-A 1$ gene inhibited the proliferation and cell cycle of cultured HUVECs.
\end{abstract}

Correspondence to: Dr Ping Shi, Department of Respiratory Medicine, Central Hospital of Guangyuan, 16 Jingxiangzi Street, Guangyuan, Sichuan 628000, P.R. China

E-mail: pingshier@163.com

Key words: ectodysplasin, transcript variant 1 gene, mutant, human umbilical vein endothelial cell, cell cycle, proliferation

\section{Introduction}

Hypohidrotic ectodermal dysplasia (HED), also known as anhidrotic ectodermal dysplasia (AED) or Christ-Siemens-Touraine Syndrome, is an X-linked recessive genetic disease (1). HED is a rare congenital genetic disorder with a birth incidence of $1 / 100,000-1 / 10,000$ (2). It is characterized by the diminution or absence of eccrine sweat glands, oligodontia and peg-shaped teeth, and hair that is sparse and fine $(1,3)$. Previous study indicates that X-linked HED (XLHED) is caused by mutations of the ectodysplasin A (EDA) gene at Xq12-13.1 (4).

The EDA gene encodes the protein ectodysplasin $\mathrm{A}$, a member of the tumor necrosis factor (TNF) ligand family, which is associated with $\mathrm{NF}-\kappa \mathrm{B}$ signaling mechanisms $(5,6)$. Bayés et al (7) indicated that the EDA gene (GenBank Gene ID: 1896) has a variant 1 transcript (EDA-A1) with a full length of 5,296 bp (NM_001399.4, GI: 54112099), which has an open reading frame of $1,176 \mathrm{bp}$, and encodes a protein with 391 amino acids. Our previous clinical and molecular study of a family with XLHED, it was showed that a missense mutation of $E D A-A 1(907 \mathrm{~A} \rightarrow \mathrm{C}$; A907C) would cause the change of a glutamine residue to a proline residue (Gln306Pro), and eukaryotic expression vectors carrying mutant $E D A-A 1$ (pcDNA3.1 (-)-EDA-A1-M) and wild-type EDA-Al (pcDNA3.1 (-)-EDA-A1-W) were constructed (8).

Human umbilical vein endothelial cells (HUVECs) are cells derived from the endothelium of veins from the umbilical cord. They are used as a laboratory model system for the study of the function and pathology of endothelial cells (9). In the present study, the effects of transfection with the EDA-Al gene and its mutant on the proliferation, cell cycle and protein expression of HUVECs were investigated.

\section{Materials and methods}

Cell culture. The ECV304 HUVECs were provided by Professor Chunming Wang (Lanzhou University, Lanzhou, China). The cells were cultured in RPMI-1640 (Huamei Biotechnique Co., Ltd., Shanghai, China). The medium included $10 \%$ fetal bovine serum (FBS; Evergreen Biological 
Engineering Materials, Co. Ltd., Hangzhou, China) and $100 \mathrm{U} / \mathrm{ml}$ penicillin/streptomycin (Gibco; Thermo Fisher Scientific Inc., Waltham, MA, USA). The cells were maintained in a humidified incubator in an atmosphere containing $5 \% \mathrm{CO}_{2}$ at $37^{\circ} \mathrm{C}$, and subjected to digestion with $0.25 \%$ trypsin (Gibco; Thermo Fisher Scientific, Inc.) overnight. Cells were maintained at $2 \times 10^{5}-1 \times 10^{6}$ cells $/ \mathrm{ml}$. An Olympus IX70 inverted microscope (Olympus Corporation, Tokyo, Japan) was used for the observation of cell morphology.

Plasmid extraction. The eukaryotic plasmids, pcDNA3.1 (-)-EDA-A1-M and pcDNA3.1 (-)-EDA-A1-W, were constructed as previously described (8). Plasmid DNA was extracted using Plasmid Extraction kit (Tiangen Biotech Co., Ltd., Beijing, China), according to the manufacturer's protocol, and $3 \mu \mathrm{l}$ DNA was subsequently diluted to $1 \mathrm{ml}$ with sterile deionized water. Absorbance (A) values at 260 and $280 \mathrm{~nm}$ were measured using a UV spectrophotometer (UV-2401, Shimadzu Corpoartion, Kyoto, Japan). The plasmid DNA concentration was calculated as follows: Plasmid DNA concentration $(\mu \mathrm{g} / \mu \mathrm{l})=\mathrm{A} 260 \mathrm{x}$ dilution factor $\mathrm{x} 50 / 1,000$. The plasmid DNA (positive recombinants and empty control) was precipitated with ethanol. Each DNA pellet was then resuspended in sterile deionized water.

Cell transfection. Transfection of the ECV304 cells was performed using the calcium phosphate co-precipitation method, according to the protocol provided with the Effectene Transfection Reagent kit (Qiagen GmbH, Hilden, Germany). Transfection was carried out when the cell density had reached $70 \%$ confluence after $24 \mathrm{~h}$ of cell-passaging. Cells were transferred into a complete medium (CM) $2 \mathrm{~h}$ prior to transfection. Then, $2.5 \mu \mathrm{g}$ plasmid DNA was slowly added to $2 \mathrm{M} \mathrm{CaCl}_{2}$ and allowed to stand for $10 \mathrm{~min}$. The DNA-CaCl solution was slowly added dropwise to $2 \mathrm{X}$ HEPES-buffered saline (HeBS), containing $280 \mathrm{mM} \mathrm{NaCl}, 1.5 \mathrm{mM} \mathrm{Na}_{2} \mathrm{HPO}_{4}$, and $50 \mathrm{mM}$ HEPES (pH 7.05), and allowed to stand for $30 \mathrm{~min}$ until tiny particles precipitated. The precipitate was uniformly dropwise added to the cells $\left(70 \%\right.$ confluence; $\sim 2 \times 10^{5}$ cells $\left./ \mathrm{ml}\right)$ in the culture flasks. After a $12-\mathrm{h}$ growth at $37^{\circ} \mathrm{C}$ in a humidified incubator containing $5 \% \mathrm{CO}_{2}$, cells were washed twice with HeBS, followed by culturing in CM. Empty vector-transfected cells were used as the control group.

Reverse transcription-polymerase chain reaction (RT-PCR). To semi-quantitatively analyze the expression levels of EDA-Al in cells, RT-PCR analysis was performed. Total RNA was extracted from the cells from each group after culturing for $48 \mathrm{~h}$, using a reverse transcription (RT) kit (Fermentas; Thermo Fisher Scientific, Inc., Pittsburgh, PA, USA). Primers for EDA-Al were designed using Primer Premier 5.0 software (Premier Biosoft, Palo Alto, CA, USA) and synthesized by Shanghai Sangon Biological Engineering Technology and Services Co., Ltd. (Shanghai, China). The primers used were as follows: EDA-A1 (408 bp), forward: 5'-CGC AGG ATC CAT GGG CTA CCC GGA GGT-3', and reverse: 5'-ATT AAG CTT GCC AAG CGG GCA CCA GGG AGA C-3'; $\beta$-actin (230 bp), forward: 5'-TTCACAGGCAGGACAGAAGA-3', and reverse: 5'-TTGAAGGTCGCAGAGTTCCT-3'. The 50- $\mu 1$ PCR reaction system comprised cDNA template $(2 \mu 1), 1 \mathrm{X}$
PCR Buffer (5 $\mu \mathrm{l})$, deoxynucleotide (dNTP; $1 \mu \mathrm{l})$, primer (forward and reverse, $1 \mu \mathrm{l}$ ), Taq DNA polymerase $(1 \mu \mathrm{l})$ and $\mathrm{ddH}_{2} \mathrm{O}(39 \mu \mathrm{l})$. RT-PCR was performed in a thermal reactor (Thermocycler, Takara Bio Inc., Otsu, Japan). Products were subjected to electrophoresis (1.5\% agarose gel, $120 \mathrm{~V}, 90 \mathrm{~mA}$ ).

Western blot analysis. In order to prepare cell lysates, cells were collected and cell extracts were prepared using radioimmunoprecipitation assay buffer, according to the manufacturer's protocol (Biotek Corporation, Beijing, China). Cell lysates were collected following centrifugation at 9,500 $\mathrm{x}$ g for $15 \mathrm{~min}$ at $4^{\circ} \mathrm{C}$, and were subsequently transferred to clean microcentrifuge tubes. For western blot analysis, proteins were extracted from the cells in each group. Proteins were collected following cell lysis. The Bradford protein assay (10) was used to confirm the protein content. The proteins were separated by $10 \%$ sodium dodecyl sulfate-polyacrylamide gel electrophoresis and transferred to a $0.45-\mu \mathrm{m}$ pore size nitrocellulose (NC) membrane (RPN303E; Amersham; GE Healthcare Life Sciences, Chalfont, UK). Membranes were blocked with Tris-buffered saline (TBS; Boster Biological Technology, Ltd., Wuhan, China) containing 5\% milk and $0.5 \%$ Tween for $1 \mathrm{~h}$ $\left(37^{\circ} \mathrm{C}\right)$, and then washed three times with $0.1 \mathrm{M} \mathrm{TBS}(\mathrm{pH} 7.6)$ with $0.1 \%$ Tween (TBST). Anti-EDA-A1 rabbit anti-serum polyclonal antibody was obtained by custom rabbit immunization using purified FLAG-EDA as the immunogen. Then, the NC membrane was treated with TBST solution (containing 2\% milk, 1:200 dilution of anti-EDA-A1 rabbit anti-serum) for $1 \mathrm{~h}$ at $37^{\circ} \mathrm{C}$, and washed with TBST three times. Following incubation with horseradish peroxidase-conjugated anti-rabbit immunoglobulin G secondary antibody (1:2,000; A6154; Sigma-Aldrich, St. Louis, MO, USA), the expression levels of the target protein were visualized with SuperSignal West Femto Maximum Sensitivity Substrate (Pierce Biotechnology, Inc., Rockford, IL, USA)

3-(4,5-Dimethylthiazol-2-yl)-2,5-diphenyltetrazolium bromide (MTT) assay for the detection of cell proliferation. To determine the proliferation of each group of ECV304 cells, an MTT assay was performed. The 24-h-infected and uninfected cells were seeded into a 96-well plate with an inoculation density of 5,000 cells/well and incubated at $37^{\circ} \mathrm{C}$. After $12 \mathrm{~h}, 100 \mu \mathrm{l}$ serum-free Dulbecco's modified Eagle's medium was added to each well. After 72 h, $20 \mu 1 \mathrm{MTT}$ was added to each well and incubation was continued at $37^{\circ} \mathrm{C}$ for $4 \mathrm{~h}$. Then, the medium was removed and the precipitate was dissolved in dimethylsulfoxide. The absorbance (optical density, OD) at $560 \mathrm{~nm}$ was measured using a SpectraMax 190 microplate reader (Molecular Devices, LLC, Sunnyvale, CA, USA). The inhibition rate of cell growth was calculated $(n=10)$ on the basis of the experimentally measured OD value.

Cell cycle analysis. Flow cytometry was used to investigate the cell cycle. Following incubation for $48 \mathrm{~h}$, the cells were collected and washed with cold phosphate-buffered saline. The washed cells were fixed in $70 \%$ cold ethanol with incubation overnight at $4{ }^{\circ} \mathrm{C}$. To stain the cells, propidium iodide (PI) solution was added. A flow cytometer (Coulter Epics XL; Beckman Coulter, Inc., Brea, CA, USA) was used to analyze the samples. CellQuest 6.0 software (BD Biosciences, San 


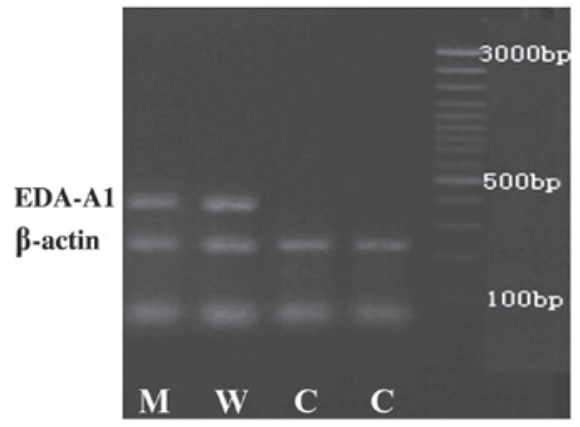

Figure 1. Detection of mRNA expression of the EDA-A1 gene in ECV304 cells transfected with wild-type (W) and mutant (M) EDA-Al gene or empty vector control $(C)$ by reverse transcription-polymerase chain reaction. EDA-A1, ectodysplasin A, transcript variant 1.

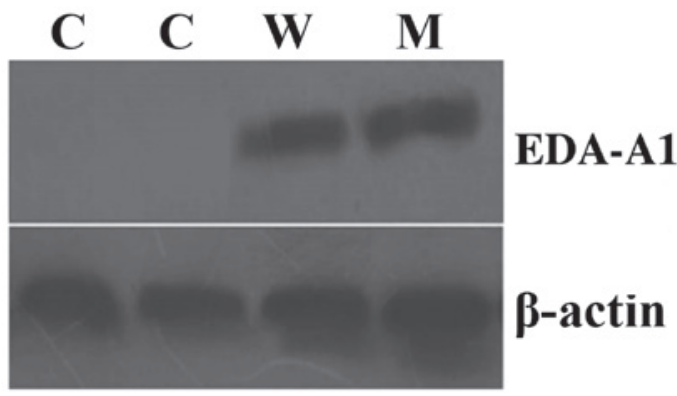

Figure 2. Detection of the expression of EDA-A1 protein in ECV304 cells transfected with wild-type (W) and mutant (M) EDA-A1 gene or empty vector control $(\mathrm{C})$ by western blotting. EDA-A1, ectodysplasin A, transcript variant 1

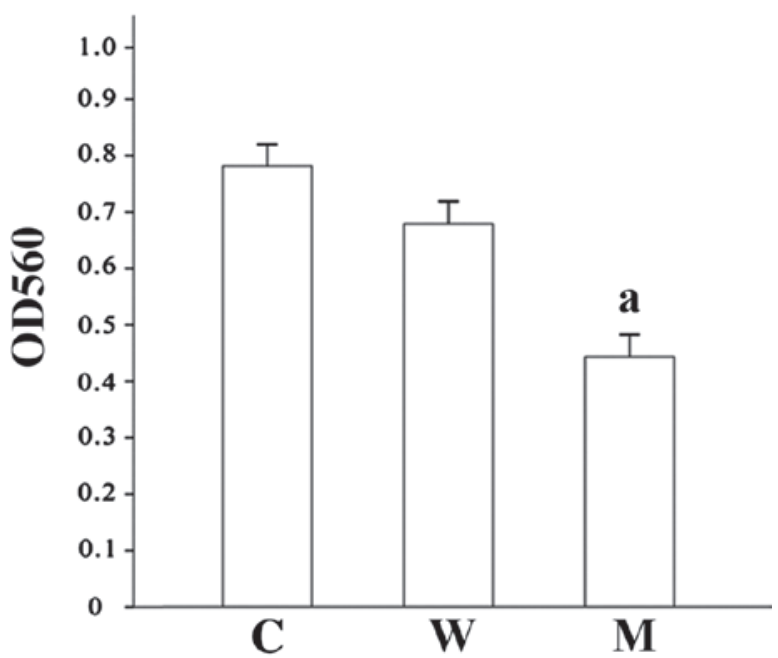

Figure 3. OD560 values of ECV304 cells transfected with wild-type (W) and mutant (M) EDA-A1 gene or empty vector control (C) after culturing for 96 h. ${ }^{a} \mathrm{P}<0.01$ vs. the control group. OD560, optical density at $560 \mathrm{~nm}$; EDA-A1, ectodysplasin A, transcript variant $1 . \mathrm{n}=10$ per group.

Jose, CA, USA) was used to analyze the percentage of cells in the $\mathrm{G}_{0} / \mathrm{G}_{1}, \mathrm{~S}$ and $\mathrm{G}_{2} / \mathrm{M}$ phases $(\mathrm{n}=5)$.

Statistical analysis. SPSS statistical analysis software, version 13.0 (SPSS, Inc., Chicago, IL, USA) was used to conduct analysis of variance testing for all data, which are
Table I. OD560 value of ECV304 cells transfected with the $E D A-A 1$ gene following $96-\mathrm{h}$ culture.

\begin{tabular}{lcc}
\hline Group & OD560 & Inhibition rate (\%) \\
\hline Control & $0.79 \pm 0.037$ & 2.5 \\
Wild type & $0.68 \pm 0.016$ & 16.0 \\
Mutant & $0.44 \pm 0.033^{\mathrm{a}}$ & $45.7^{\mathrm{a}}$ \\
\hline
\end{tabular}

${ }^{a} \mathrm{P}<0.01$ vs. the control group. OD560, optical density at $560 \mathrm{~nm}$; EDA-Al, ectodysplasin A, transcript variant 1.

expressed as the mean \pm standard deviation. P-values less than 0.05 were considered to indicate a statistically significant difference.

\section{Results}

EDA-A1 expression pattern in ECV304 cells is influenced by plasmid-mediated transfection. To determine the expression level of EDI-Al in the transfected ECV304 cells, the RNA samples with an OD260/OD280 ratio of 1.8-2.0 were selected for RT-PCR. The ECV304 cells transfected with pcDNA3.1 (-)-EDA-A1-M or pcDNA3.1 (-)-EDA-A1-W showed a band at $\sim 400$ bp that was not observed for the empty vector-transfected control cells when examined using semi-quantitative PCR and primers specific to EDA-Al (Fig. 1). Additionally, a $\beta$-actin band between $200 \mathrm{bp}$ and 300 bp was observed for all groups. Then, EDA-A1 protein expression levels in the ECV304 cells were detected by western blotting. Fig. 2 shows that the EDA-A1 protein was expressed in the cells infected with pcDNA3.1 (-)-EDA-A1-M or pcDNA3.1 (-)-EDA-A1-W vector, but was not expressed in the control group. In conclusion, EDA-Al mRNA and protein was expressed in ECV304 cells following the exogenous delivery of EDA-Al, but not in control cells.

Overexpression of EDA-Al affects ECV304 cell proliferation. To elucidate whether EDA-Al has an effect on ECV304 cell proliferation, MTT assays were performed. As shown in Fig. 3, the ECV304 cell viability at $96 \mathrm{~h}$ infection was decreased significantly in the mutant group by comparison with that in the wild type and control groups. The proliferation of mutant group cells was suppressed by $45.7 \%$ relative to control, while the proliferation of the wild type group was suppressed by 16.0\% (Table I, Fig. 3).

EDA-A1 overexpression regulates the cell cycle of ECV304 cells. To determine the effect of plasmid-mediated EDA-AI infection on the cell cycle of ECV304 cells, flow cytometric analysis was conducted (Fig. 4). It was observed that $25.45 \pm 1.89 \%$ of cells were arrested at the $\mathrm{G}_{0} / \mathrm{G}_{1}$ phase of the cell cycle in the mutant group, compared with $20.37 \pm 0.68$ and $20.30 \pm 0.68 \%$ of cells in the wild type and control groups, respectively (Table II). During the S phase, the mutant and wild type groups showed significantly higher cell percentages (12.40 \pm 1.75 and $14.80 \pm 1.45 \%$, respectively) than the control group (8.55 $\pm 0.57 \%)$. However, the two EDA-Al-transfected 
Table II. Effect of EDA-A1 gene transfection on the cell cycle of ECV304 cells.

\begin{tabular}{lccc}
\hline Group & $\mathrm{G}_{0} / \mathrm{G}_{1}$ phase & S phase & $\mathrm{G}_{2} / \mathrm{M}$ phase \\
\hline Control & $20.30 \pm 0.68$ & $8.55 \pm 0.57$ & $71.15 \pm 0.57$ \\
Wild type & $20.37 \pm 0.68$ & $14.80 \pm 1.45^{\mathrm{a}}$ & $64.83 \pm 0.85^{\mathrm{a}}$ \\
Mutant & $25.45 \pm 1.89^{\mathrm{a}, \mathrm{b}}$ & $12.40 \pm 1.75^{\mathrm{a}}$ & $62.15 \pm 1.94^{\mathrm{a}}$ \\
\hline
\end{tabular}

${ }^{\mathrm{a}} \mathrm{P}<0.05$ vs. the control group; ${ }^{\mathrm{b}} \mathrm{P}<0.05$ vs. the wild type group. EDA-A1, ectodysplasin $\mathrm{A}$, transcript variant 1.

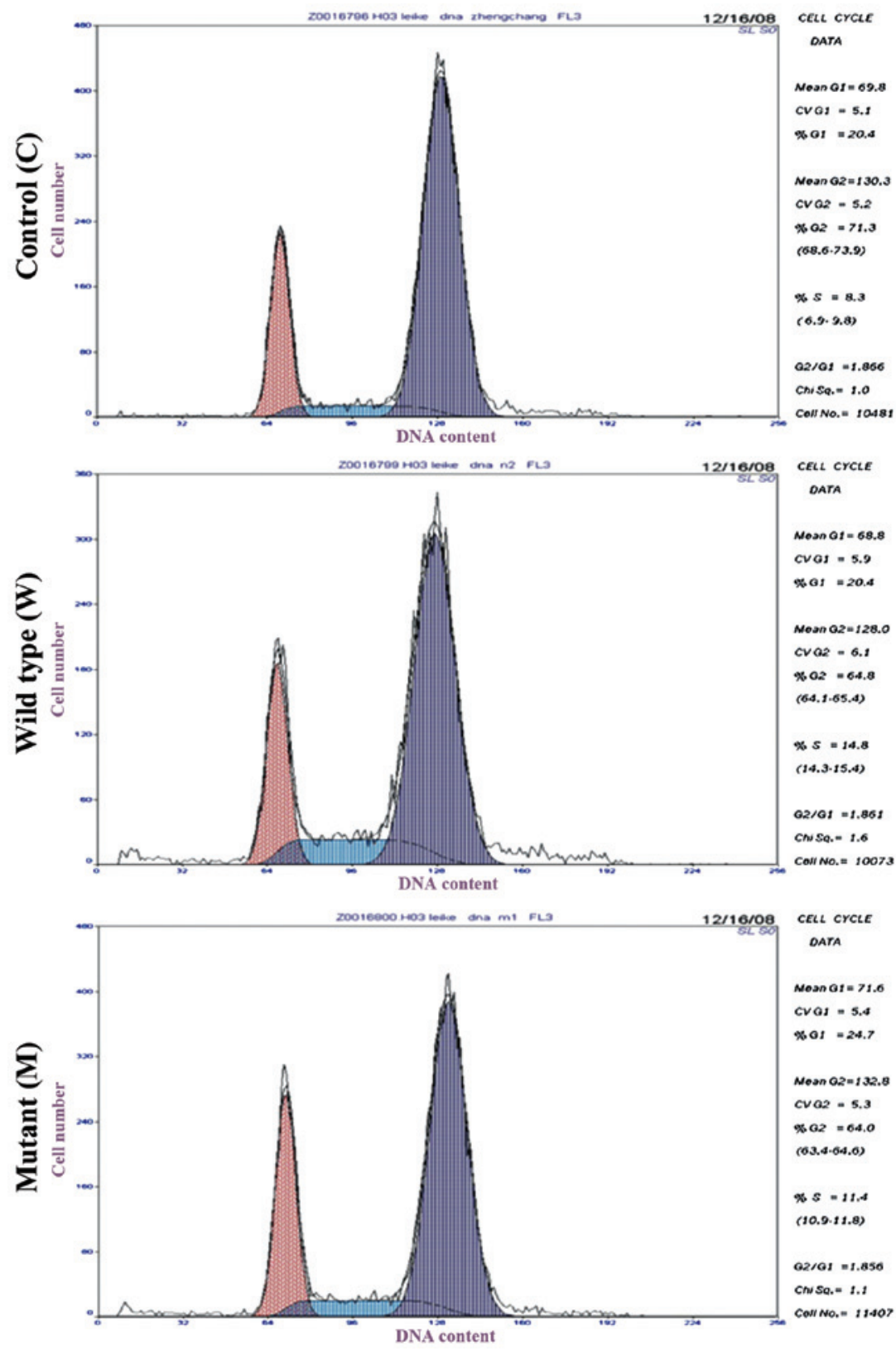

Figure 4. Effect of EDA-A1 gene transfection on the cell cycle of ECV304 cells as shown by flow cytometry. EDA-A1, ectodysplasin A, transcript variant 1.

groups had lower cell percentages than the control in the $\mathrm{G}_{2} / \mathrm{M}$ phase. The lowest cell percentage in the $\mathrm{G}_{2} / \mathrm{M}$ phase was $62.15 \pm 1.94 \%$ in the mutant group. It may be concluded that the cell cycle distribution in the $\mathrm{G}_{0} / \mathrm{G}_{1}, \mathrm{~S}$ and $\mathrm{G}_{2} / \mathrm{M}$ phases of ECV304 cells were regulated by $E D A-A 1$ overexpression.

\section{Discussion}

Until now, the exact pathological mechanism of HED has remained unclear. In the present study, the effect of a HED-associated gene (EDA-Al) on the proliferation and cell 
cycle of ECV304 cells was investigated. The results indicated that mutant and wild-type EDA-Al genes might have distinct biological functions affecting the proliferation and cell cycle distribution of cultured HUVECs.

$E D A-A 1$, which is a variant of the major causative gene of $\operatorname{HED}(E D A)$, is located on chromosome Xq12-13.1 and encodes a protein containing 391 amino acids $(4,11)$. The EDA-A1 protein, a type II transmembrane protein, is a member of the TNF ligand family. It consists of a short extracellular domain, a transmembrane region, a collagen area, and a TNF ligand subunit (6,11-13). The combination of EDA-A1 and the ectodysplasin receptor can promote programmed cell death and activate NF- $\kappa \mathrm{B}$ signaling $(11,14)$.

Currently, the research relating to HED mostly comprises case reports and mutation analysis; however, few studies have reported on the function of the $E D A-A l$ gene, particularly in cell activity. Immunohistochemical analysis of human MCF-7 and COS-1 cells transfected with pCMV5-EDA-A2 identified strong signals at the cell surface for some transfected cells, and changes in the cell morphology of MCF-7 were found to be associated with the expression of EDA-A2 (7). Another previous study demonstrated that pIRES2-EGFP-EDA eukaryotic plasmids could be successfully transfected into dental pulp mesenchymal cells and stably expressed (15). In the present study, compared with the control group, the proliferation of ECV304 cells in the mutant group was decreased significantly, and cell growth was inhibited. This may be due to a change in the spatial configuration and biological activity of the EDA-A1 protein caused by the EDA-Al gene mutation. However, the reduction of cell proliferation of the ECV304 cells transfected with wild-type $E D A-A l$ was not significant.

The cell cycle, which consists of a series of highly ordered phases $\left(G_{1}, S, G_{2}\right.$ and $\left.M\right)$, is important to both normal and cancer cells (16). The actions of antitumor agents are also characterized by an association with cell cycle phase (17). The results of the present study indicated that the EDA-Al gene mutant had an impact on the cell cycle, and blocked cell cycle progression in the $G_{0} / G_{1}$ and $S$ phases. However, the present study was limited, since it lacked transfection experiments with oral-related cell lines.

In conclusion, the present study revealed the inhibitory effect of an EDA-Al gene mutant on the proliferation of ECV304 cells. The aim of our future research is to focus on the transfection of the EDA-Al gene in other oral cavity-related cell lines, and to further elucidate the effect of the EDA-AI gene on tooth, jaw and craniofacial development.

\section{References}

1. Clarke A, Phillips D, Brown R and Harper PS: Clinical aspects of X-linked hypohidrotic ectodermal dysplasia. Arch Dis Child 62: 989-996, 1987.

2. Callea M, Vinciguerra A, Willoughby CE, Deroma L and Clarich G: Infantile bilateral glaucoma in a child with ectodermal dysplasia. Ophthalmic Genet 34: 58-60, 2013.

3. Yildirim M, Yorgancilar E, Gun R and Topcu I: Ectodermal dysplasia: Otolaryngologic evaluation of 23 cases. Ear Nose Throat J 91: E28-E33, 2012.

4. Mues G, Tardivel A, Willen L, Kapadia H, Seaman R, Frazier-Bowers S, Schneider P and D'Souza RN: Functional analysis of ectodysplasin-A mutations causing selective tooth agenesis. Eur J Hum Genet 18: 19-25, 2010.

5. Mikkola ML: Molecular aspects of hypohidrotic ectodermal dysplasia. Am J Med Genet A 149A: 2031-2036, 2009.

6. Ulvmar MH, Sur I, Mémet S and Toftgård R: Timed NF-kappaB inhibition in skin reveals dual independent effects on development of HED/EDA and chronic inflammation. J Invest Dermatol 129: 2584-2593, 2009.

7. Bayés M, Hartung AJ, Ezer S, Pispa J, Thesleff I, Srivastava AK and Kere J: The anhidrotic ectodermal dysplasia gene (EDA) undergoes alternative splicing and encodes ectodysplasin-A with deletion mutations in collagenous repeats. Hum Mol Genet 7: 1661-1669, 1998.

8. Lei K, Che TJ, Wang JM, Deng N, Zhang L and He XY: Mutation analysis of the eda-A1 gene for hypohidrotic ectodermal dysplasia and construction of recombined eukarytoic expression vector. Hua Xi Kou Qiang Yi Xue Za Zhi 27: 610-613, 2009 (In Chinese).

9. Park HJ, Zhang Y, Georgescu SP, Johnson KL, Kong D and Galper JB: Human umbilical vein endothelial cells and human dermal microvascular endothelial cells offer new insights into the relationship between lipid metabolism and angiogenesis. Stem Cell Rev 2: 93-102, 2006.

10. Kruger NJ: The Bradford method for protein quantitation. In: Methods in Molecular Biology: Basic Protein and Peptide Protocols. Walker JM (ed). Vol 32. Humana Press, Totawa, NJ, pp9-15, 1994.

11. Cluzeau C, Hadj-Rabia S, Jambou M, Mansour S, Guigue P, Masmoudi S, Bal E, Chassaing N, Vincent MC, Viot G, et al: Only four genes (EDA1, EDAR, EDARADD, and WNT10A) account for $90 \%$ of hypohidrotic/anhidrotic ectodermal dysplasia cases. Hum Mutat 32: 70-72, 2011.

12. Hashimoto T, Cui CY and Schlessinger D: Repertoire of mouse ectodysplasin-A (EDA-A) isoforms. Gene 371: 42-51, 2006.

13. Ezer S, Schlessinger D, Srivastava A and Kere J: Anhidrotic ectodermal dysplasia (EDA) protein expressed in MCF-7 cells associates with cell membrane and induces rounding. Hum Mol Genet 6: 1581-1587, 1997.

14. Courtney JM, Blackburn J and Sharpe PT: The ectodysplasin and NFkappaB signalling pathways in odontogenesis. Arch Oral Biol 50: 159-163, 2005.

15. Gan YN, Wang ZY, Chen SM, Zhao GW, Ye XL and Shen LJ: Establishment of human dental papilla mesenchymal cells stably-transfected with EDA gene. Kouqiang Yixue 26: 270-272, 2006 (In Chinese).

16. Evan GI and Vousden KH: Proliferation, cell cycle and apoptosis in cancer. Nature 411: 342-348, 2001

17. Bhuyan BK, Scheidt LG and Fraser TJ: Cell cycle phase specificity of antitumor agents. Cancer Res 32: 398-407, 1972. 